Notas Clínicas

\title{
Tumor desmoplásico de células pequeñas y redondas (DSRCT) de riñón
}

\author{
C. M. Cabrera Morales
}

\section{Resumen}

El tumor desmoplásico de células pequeñas y redondas es una rara enfermedad que afecta a la cavidad peritoneal, normalmente se presenta en chicos jóvenes, y se caracteriza por la presencia de células pequeñas e indiferenciadas con núcleos hipercromáticos. Esta entidad se distingue del resto de tumores de células pequeñas y redondas por la co-expresión histoquímica de antígenos epiteliales, musculares, y neuronales. La translocación $\mathrm{t}(11 ; 22)$ (p13;q12) es una característica recurrente de este tipo de neoplasias. Presentamos un nuevo caso de tumor desmoplásico de células pequeñas y redondas de riñón diagnosticado en un joven de 20 años de edad, en el cual por técnicas de hibridación in situ fluorescente (FISH) no se encontró la translocación t(11;22) (p13;q12).

\section{Palabras clave}

Tumor desmoplásico de células pequeñas y redondas. FISH. Translocación. EWS1. WT1.

Oncología, 2005; 28 (5):244-248

Servicio de Análisis Clínicos e Inmunología y Servicio de Anatomía Patológica Hospital Universitario Virgen de las Nieves

Granada 


\section{Summary}

Desmoplastic small round cell tumor is a rare disease consisting of a form of peritoneal surface malignancy usually affecting young males, composed of relatively small and undifferentiated cells with a high nuclearcytoplasmic ratio. The co-expression of epithelial, muscular and neuronal antigens distinguishes this entity from other small round cell tumors. The $\mathrm{t}(11 ; 22)(\mathrm{p} 13 ; \mathrm{q} 12)$ translocation is a recurrent characteristic of this type of tumor. However, we report a new case of desmoplastic small round cell tumor of the kidney affecting a 20 year old male where the $\mathrm{t}(11 ; 22)(\mathrm{p} 13 ; \mathrm{q} 12)$ is absent.

Key words: Desmoplastic small round cell tumor. FISH. Translocation. EWS1. WT1.

\section{Introducción}

Los sarcomas de partes blandas son tumores poco frecuentes que constituyen alrededor del $1 \%$ de los casos de cáncer humano ${ }^{1}$. Es más frecuente su aparición alrededor de los 50 años de edad, pero no hay una edad específica de comienzo. Dentro de ellos el tumor desmoplásico de células pequeñas y redondas (desmoplastic small round cell tumor, DSRCT) constituye una rara entidad de extrema agresividad $^{2}$, recientemente descrita y reconocida que afecta principalmente a niños y adultos jóvenes ${ }^{3}$, con una edad promedio de aparición de 21 años y con una elevada prevalencia en hombres ${ }^{4}$. Es una neoplasia que afecta difusamente al peritoneo abdominal o pélvico, aunque se han descrito casos en otras localizaciones con una frecuencia baja (pleura, túnica vaginalis, SNC, hígado, ovario, etc) ${ }^{5}$. La histología típica se caracteriza por la presencia de nidos o trabéculas de células tumorales embebidos en un estroma fibroso. No es infrecuente observar necrosis en el centro de los nidos de mayor tamaño. Su principal característica diagnóstica es la co-expresión de marcadores epiteliales, musculares, y neuronales ${ }^{6}$, así como la presencia de la translocación recíproca $\mathrm{t}(11 ; 22)(\mathrm{p} 13 ; \mathrm{q} 12)$ que afecta a los genes EWS1 (gen del sarcoma de Ewing) y WT1 (gen del tumor de Wilms) ${ }^{7,8}$.

Presentamos el segundo caso de tumor desmoplásico de células pequeñas y redondas de riñón descrito en la literatura ${ }^{9}$, en el que por técnicas de FISH no se ha encontrado la translocación característica de este tipo de tumores.

\section{Caso clínico}

Paciente de 20 años de edad que acude a urgencias, con dolor lumbar y fiebre. Al paciente se le realizan urocultivos, hemocultivos, y estudio de marcadores tumorales (pruebas que resultan negativas), por tomografía axial computerizada (TAC) se le detecta una masa tumoral que afecta al polo superior del riñón derecho (Fig. 1). Tras lo cual se realiza la resección quirúrgica del tumor.

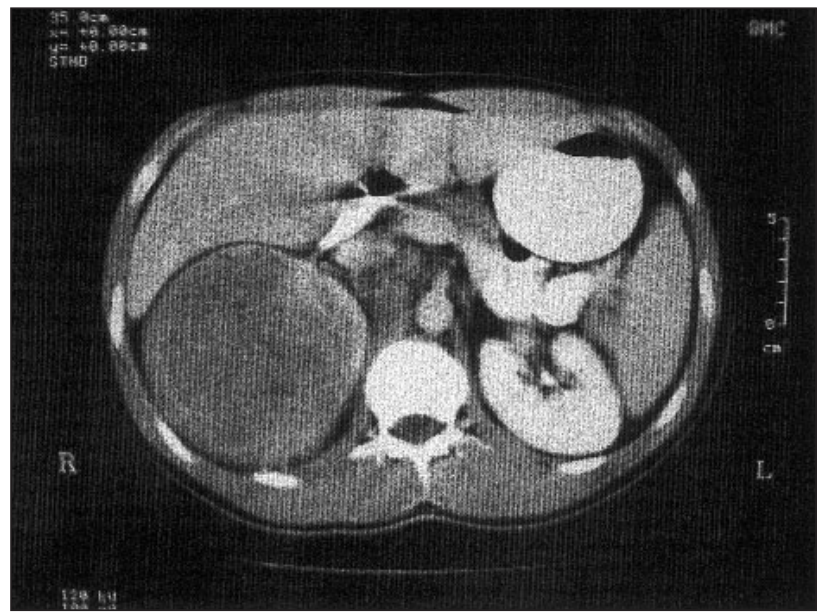

Figura 1. TAC abdominal: masa hipodensa en riñón derecho.

La pieza de resección quirúrgica estaba constituida por una masa tumoral de $14 \mathrm{~cm}$ de diámetro mayor, con infiltración del polo superior y segmento medio renales, y afectación del seno y sistema pielocalicial. Se observó presencia de invasión vascular 


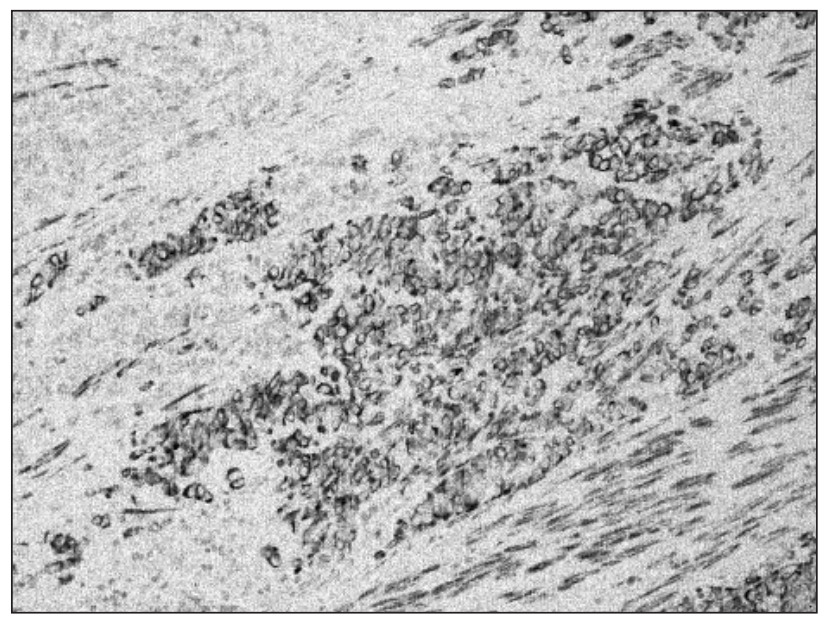

Figura 2. Técnica de inmunohistoquímica positiva para desmina (HE x200).

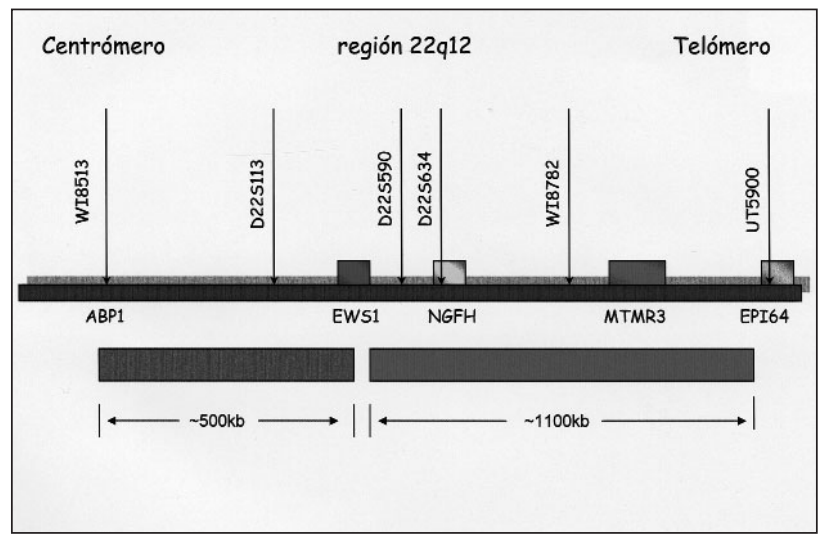

Figura 3. Estructura génica de la región cromosómica 22q12. La sonda naranja marcada con Spectrum-Orange de $\sim 500 \mathrm{~Kb}$ flanquea la región 5' del gen EWS1, la sonda verde de $\sim 1.100 \mathrm{~kb}$ marcada con Spectrum-Green flanquea la región 3' del gen.

linfática tumoral en el tejido renal y grasa adyacente. Metástasis medular de glándula suprarrenal, invasión de la grasa perirrenal y nódulos de la cadena interaórtico cava.

Mediante la realización de técnicas de inmunohistoquímica sobre secciones de parafina con diferentes anticuerpos monoclonales (Dako) se encontró el siguiente patrón de tinción compatible con un tumor desmoplásico de células pequeñas y redondas: citoqueratinas 8,18 y $19(+)$, proteína ácida fibrilar glial $(-)$, desmina (+) (Fig. 2), vimentina (+), sinaptofisina $(+)$, cromogranina (-), actina (débilmente + ), y S100 (débilmente + ).

Se realizó igualmente el estudio citogenético de la

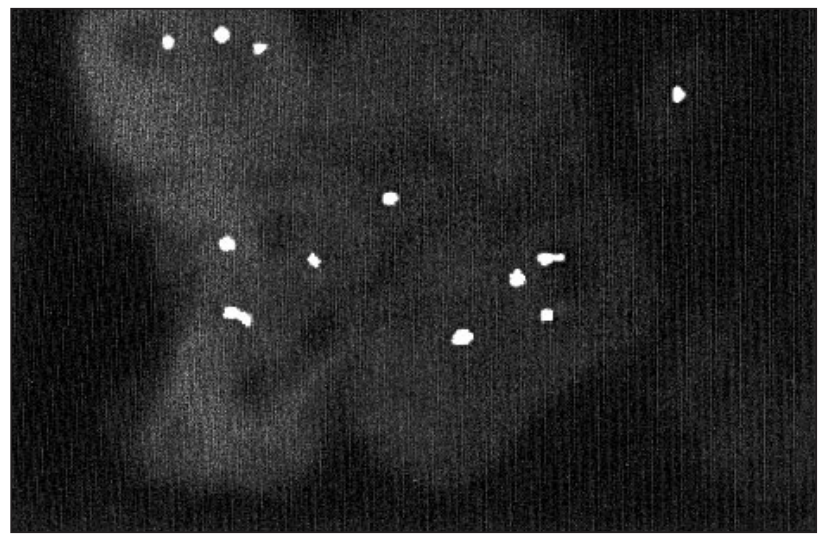

Figura 4. Células tumorales del paciente en estado de interfase marcadas con el kit LSI EWSR1 Dual Color, que muestran dos señales de fusión rojo-verde por célula, indicativo de ausencia de cualquier translocación que afecte al gen EWS1.

translocación $\mathrm{t}(11 ; 22)(\mathrm{p} 13 ; \mathrm{q} 12)$ que implica a los genes EWS1 y WT1 mediante hibridación in situ fluorescente (FISH), para ello se utilizó el kit LSI EWSR1 (22q12) Dual Color Break Apart Rearrangement Probe (VYSIS). El cual está constituido por una mezcla de dos sondas que flanquean completamente el locus del gen EWS1 (Fig. 3), la sonda más centromérica está marcada con Spectrum-Orange y las más telomérica con Spectrum-Green. Como resultado de este diseño cualquier translocación en la que esté implicado el locus EWS1 produce la separación de la señal de fusión rojo-verde en una señal roja y otra verde. El patrón observado en nuestro caso se corresponde con el patrón de normalidad, con presencia de dos señales de fusión roja-verde por cada célula tumoral (Fig. 4), confirmando por tanto la ausencia de translocación en el paciente.

El paciente fue tratado con tres ciclos de CAV, cuatro ciclos de Ifosfamida/VP-16, y posteriormente CTX, ADR, y VCR. Como resultado de este tratamiento no se detecta infiltración tumoral en médula ósea. Sin embargo posteriormente se le detectó por TAC reaparición del tumor y metástasis hepática. Tras lo cual no se produce respuesta al tratamiento y el paciente fallece a los dos años del diagnóstico inicial.

\section{Discusión}

El término "tumor de células pequeñas y redondas" (small round cell tumor) describe a un grupo de tumores malignos altamente agresivos formado por 
células pequeñas e indiferenciadas con núcleos hipercromáticos redondos u ovales, nucleolos poco evidentes y citoplasma escaso ${ }^{4}$. Este grupo incluye el sarcoma de Ewing (ES), neuroepitelioma periférico, neuroblastoma periférico, rabdomiosarcoma, tumor desmoplásico de células pequeñas y redondas, linfoma, leucemia, osteosarcoma de células pequeñas, carcinoma de células pequeñas, y melanoma maligno, entre otros ${ }^{10}$. Para la distinción entre sarcomas, carcinomas, y linfomas se emplean tres marcadores muy útiles: el antígeno pan-leucocitario CD45 (específico de linfomas), citoqueratinas (presentes en tumores de origen epitelial y algunos sarcomas), y el filamento intermedio vimentina (presente en la mayoría de los tumores mesenquimales y en algunos carcinomas).

El tumor desmoplásico de células pequeñas y redondas es una entidad distinguible dentro de este grupo por su comportamiento histoquímico y por la presencia de abundante estroma desmoplásico ${ }^{11}$. La distinción de este tumor se logra mediante inmunohistoquímica para marcadores epiteliales (queratina, antígeno de la membrana citoplasmática de células epiteliales), neuronales (enolasa neuro-específica), y musculares (desmina). Igualmente la translocación recíproca t $(11 ; 22)(\mathrm{p} 13 ; \mathrm{q} 12)$ que implica al producto del gen EWS1 y WT1 es una característica recurrente y específica de este tipo de sarcomas ${ }^{7,8}$.

Los reordenamientos cromosómicos que afectan al gen EWS1 localizado en la región cromosómica 22q12 (Fig. 3) se han observado en diferentes tipos de tumores ${ }^{12}$. Aproximadamente el $90 \%$ de las translocaciones que afectan al gen EWS1 producen la translocación $\mathrm{t}(11 ; 22)(\mathrm{q} 24 ; \mathrm{q} 12)$ que yuxtapone a EWS1 con el gen FLI ${ }^{13}$. La segunda translocación más frecuente implica a EWS1 y ERG ${ }^{14}$, representando la translocación con WT1 un porcentaje muy pequeño. El gen WT1 codifica una proteína de unión al DNA que actúa como un factor de transcripción, y que igualmente interviene durante el proceso de diferenciación y desarrollo del sistema genitourinario y tejidos mesoteliales ${ }^{15}$. WT1 es un gen supresor de tumor que participa en el desarrollo de un subgrupo de tumores de Wilms ${ }^{15}$.

En el caso clínico presentado, el estudio de la translocación específica presente en la gran mayoría de tumores desmoplásicos de células pequeñas y redondas ${ }^{16}$ investigado mediante la técnica de FISH resultó ser negativo, revelando la ausencia de trans- locación en el paciente (Fig. 4). Por lo tanto este caso raro hay que incluirlo dentro del pequeño porcentaje de tumores desmoplásicos de células pequeñas y redondas con ausencia de translocación t $(11 ; 22)$ $(\mathrm{p} 13 ; \mathrm{q} 12)^{16}$.

\section{Conclusión}

El tumor desmoplásico de células pequeñas y redondas constituye un pequeño porcentaje dentro del grupo de los sarcomas, que comparte con ellos un origen histológico incierto y que presenta características histoquímicas definidas. Si bien la translocación $\mathrm{t}(11 ; 22)(\mathrm{p} 13 ; \mathrm{q} 12)$ que fue primeramente descrita por Gerald y col. ${ }^{17}$ como característica distintiva está presente en la gran mayoría de los casos hasta ahora publicados ${ }^{16}$, está ausente en el caso que presentamos. Pudiendo existir otras alteraciones citogenéticas que puedan tener relevancia en ese pequeño porcentaje de casos restantes.

\author{
Correspondencia: \\ Dra. C. M. Cabrera \\ Hospital Universitario Virgen de las Nieves \\ Servicio de Anatomía Patológica \\ Edificio de Gobierno - $4^{\text {a }}$ Planta \\ Avenida Fuerzas Armadas, 2 \\ E-18014 Granada \\ E-mail: mcabrm@fundacionhvn.org
}




\section{Bibliografía}

1. Fletcher JA. Cytogenetics and experimental models of sarcomas. Curr Opin Oncol 1994; 6:367-371.

2. Gerald WL, Miller HK, Battifora H, Miettinen M, Silva EG, Rosai J. Intra-abdominal desmoplastic small round cell-tumor. Report of 19 cases of a distinctive type of highgrade polyphenotypic malignancy affecting young individuals. Am J Surg Pathol 1991; 15:499-513.

3. Gerald WL, Rosai J. Case 2: desmoplastic small cell tumor with divergent differentiation. Pediatr Pathol 1989; 9:177183.

4. Kretschmar C, Colbach C, Bhan I. Desmoplastic small cell tumor. A report off three cases and a review of the literature. J Ped Haematology-Oncology 1996; 18:293-298.

5. Gil A, Gomez Portilla A, Brun EA, Sugarbaker PH. Clinical perspective on desmoplastic small round-cell tumor. Oncology 2004; 67:231-242.

6. Gerald WL, Rosai J. Desmoplastic small cell tumor with multi-phenotypic differentiation. Zentralbl Pathol 1993; 139:141-151.

7. Gerald WL, Rosai J, Ladanyi M. Characterization of the genomic breakpoint and chimeric transcripts in the EWSWT1 gene fusion of desmoplastic small round cell tumor. Proc Natl Acad Sci USA 1995; 92:1028-1032.

8. Benjamin LE, Fredericks WJ, Barr FG, Rauscher FJ 3rd. Fusion of the EWS1 and WT1 gene as a result of the $\mathrm{t}(11 ; 22)(\mathrm{p} 13 ; \mathrm{q} 12)$ translocation in desmoplastic small round cell tumor. Med Pediatr Oncol 1996; 27:434-439.

9. Su MC, Jeng YM, Chu YC. Desmoplastic small round cell tumor of the kidney. Am J Surg Pathol 2004; 28:1379-1383.
10. Devoe K, Weidner N. Immunohistochemistry of small round-cell tumors. Semin Diagn Pathol 2000; 17:216224.

11. Leuschener I, Radig K, Harms D. Desmoplastic small round cell tumor. Semin Diagn Pathol 1996; 13:204-212.

12. Sandberg AA, Brigde JA. Updates on cytogenetics and molecular genetics of bone and soft tissue tumors: Ewing sarcoma and peripheral primitive neuroectodermal tumors. Can Genet Cytogenet 2000; 123:1-26.

13. Arvand A, Denny CT. Biology of EWS/ETS fusion in Ewing's family tumors. Oncogene 2001; 20:5747-5754.

14. Sorensen PH, Lessnick SL, López-Terrada D, Liu XF, Triche TJ, Denny CT. A second Ewing's sarcoma translocation $\mathrm{t}(21 ; 22)$, fuses the EWS gene to another ETS-family transcription factor, ERG. Nat Genet 1994; 6:146151.

15. Gessler M, Poustka A, Cavenee W, Neve RL, Orkin SH, Bruns GA. Homozygous deletion in Wilms tumours of a zinc-finger gene identified by chromosome jumping. Nature $1990 ; 343: 774-778$.

16. Gerald WL, Ladanyi M, de Alava E, Cuatrecasas M, Kushner BH, LaQuaglia MP, Rosai J. Clinical, pathologic, and molecular spectrum of tumors associated with $\mathrm{t}(11,22)$ (p13,q12): desmoplastic small round-cell tumor and its variants. J Clin Oncol 1998; 16:3028-3036.

17. Gerald WL, Rosai J, Ladanyi M. Characterization of the genomic breakpoint and chimeric transcripts in the EWSWT1 gene fusion of desmoplastic small round cell tumor. Proc Natl Acad Sci 1995; 92:1028-1032. 